The last owner of the mare had only possessed her for three weeks, during which time she had been in excellent health and working order.

She had been bought off a farm.

\title{
SUCCESSFUL AMPUTATION OF THE LEG OF A COW.
}

$$
\text { By F. НовиAу, M.R.C.V.S. }
$$

ON the 20th of June 1893 , I was called in to attend a red and white shorthorn heifer, which was suffering from a very severe lacerated transverse cut at the back and upper part of the fetlock of the left fore leg, supposed to have been done with a sharp stone in a brook.

The cut had extended completely to the bone, severing both the tendons, the artery, the vein, and the nerve, and almost passing through the superior suspensory ligament.

On the 13th of June, immediately after the injury had been done, the wound had been sutured and antiseptically dressed. No union had taken place, although the limb had been kept quiet by means of splints and bandages. There was a large clot of blood over the seat of injury ; foetid odour.

2oth June.-Washed the wound, dressed it antiseptically, and replaced splints and bandage.

This treatment was supplied daily till the $23 \mathrm{rd}$, when, on undoing the bandage, visible signs of gangrene of the structures below the fetlock were noticed. Thinking that the only chance of saving the life of the animal would be to amputate the limb, and after some consultation with the owner (who wished to have the animal destroyed), the operation was decided upon. With the assistance of $\mathrm{Mr}$ Lennox-Conyngham I severed the ligaments of the fetlock joint and the skin at the front' part of the joint with a sharp knife, afterwards removing as much as possible of the necrosed tissue. There was only very slight hremorrhage, and the animal scarcely gave any evidence of pain. The bone protruded quite bare for about three inches. The whole of the parts were then wrapped in wadding soaked in carbolised oil and carefully bandaged.

$24 t h$ June.-Leg swollen up to the knee. The raw parts were yellowish red in colour, and discharging a small quantity of pus. The cow was feeding well and looked healthy. Redressed and bandaged as before.

25th June.-Ieg swollen as on 24th. More purulent discharge. Small reddish granulations appearing. Cow eating well. Redressed and bandaged.

26 th June.-Leg.slightly less swollen. Granulations distinctly visible. Good whitish pus sticking to the lint.

The protruding piece of bone at the joint beginning to turn black. Cow eating well. Pulse, respiration, and temperature normal. Dressed and bandaged as before.

27th June.-Leg less swollen. Crimson-lake granulations with healthy pus. Protruding bone more black. Skin growing down in front towards the end of the protruding bone.

Cow eating well and quite healthy. Dressed and bandaged. 
Journal of Comparative Pathology and Therapeutics.

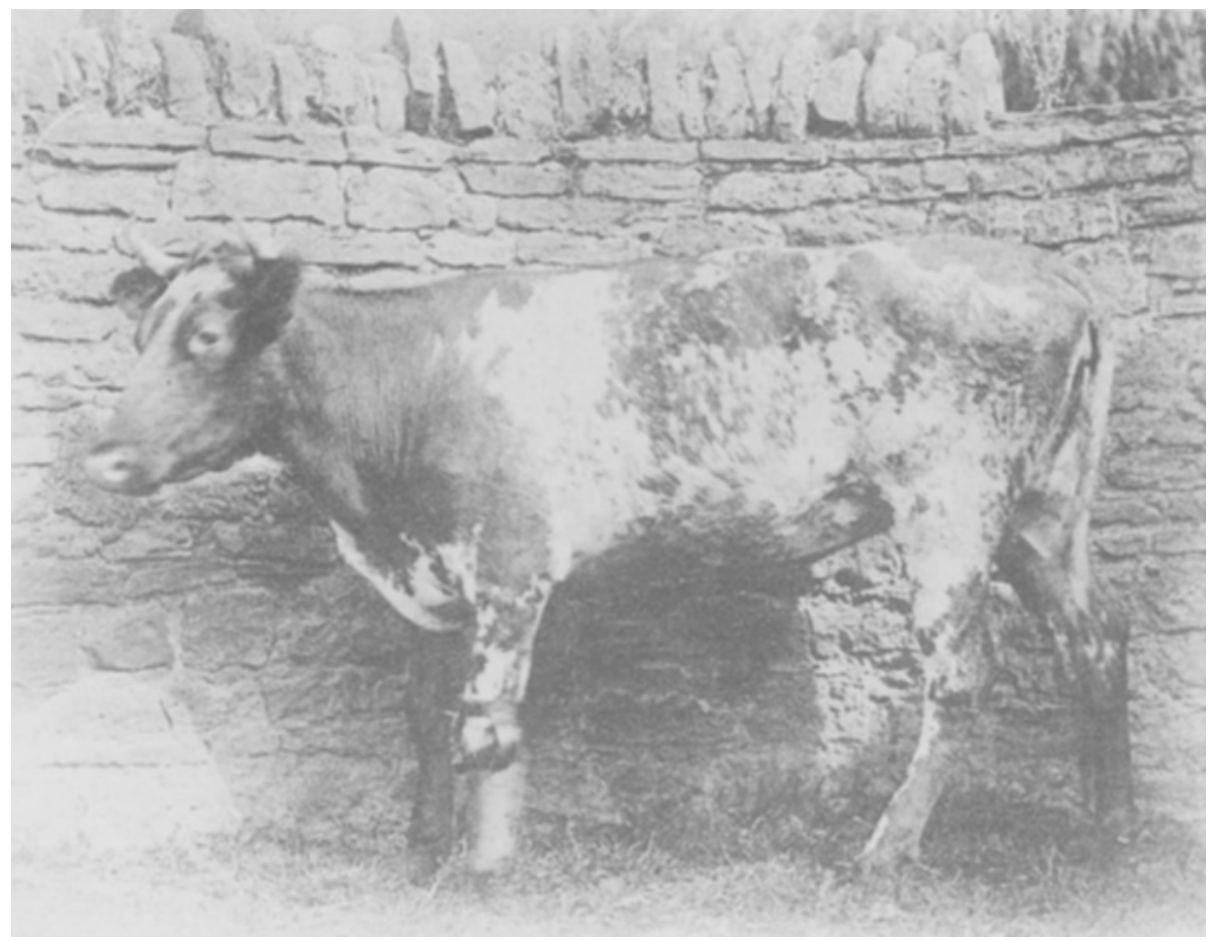

FIG. I.-Professor Hobday's case of Amputation.

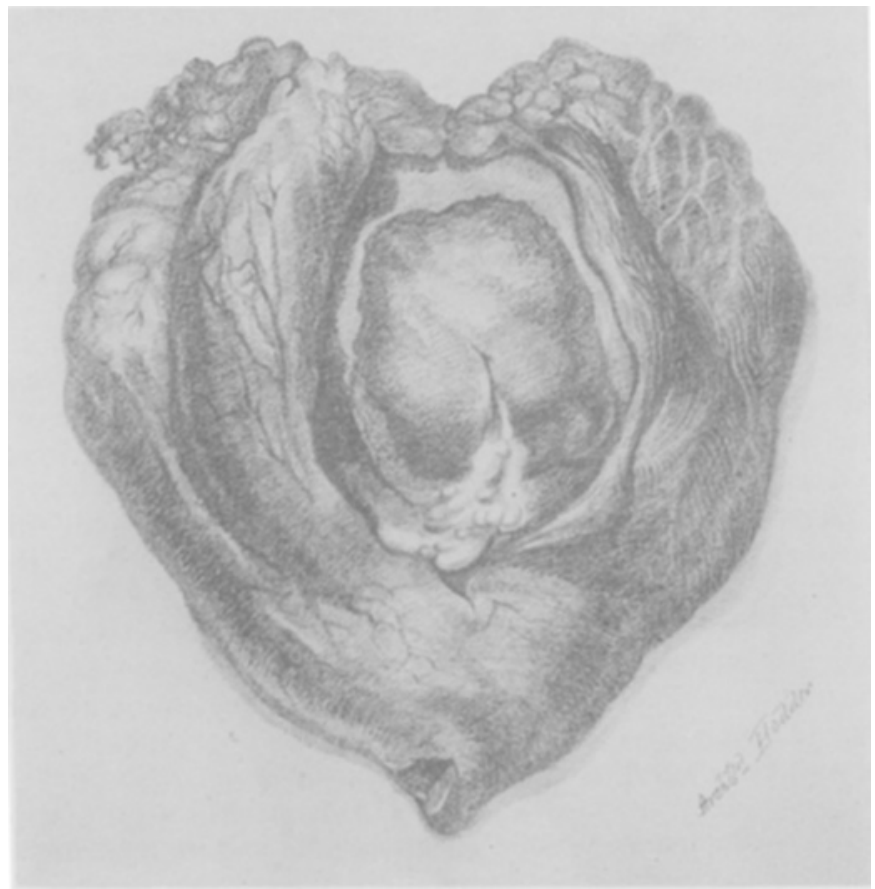

Fig. 2,-Heart of Cow laid open to expose an Abscess in the ventricular septum. 
This treatment was continued daily till Ist July, when liq. bituminis lotion ( $1-20$ ) was applied daily. The left epiphysis of the protruding bone came off.

I 4 th July. - Healthy granulations had quite covered the bone; applied liq. bitum. lotion and dry dressing every two days.

22nd July.-Was so far healed as to be measured for a leather socket to fit on the extremity in order to supply the place of the lost digits.

The bottom of the socket was carefully padded with wadding and horse-hair, and applied to the limb on the 26th.

The photograph (Fig. I, Plate VI.) was taken on the 22nd of August, and the animal has progressed very favourably, and apparently suffered very little inconvenience from the loss of her foot.

\section{Alustrants.}

\section{AN EPIDEMIC OF TYPHOID CAUSED BY MILK.}

An epidemic of typhoid broke out in the two prisons of Strasburg in I880, after twenty years freedom from that disease. All the patients attacked with typhoid in that year had consumed milk from a particular locality. Of those who had used this milk once or oftener 17 per cent. were attacked with typhoid, whereas out of 300 other persons who did not use the milk not one was attacked with typhoid. The milk had been consumed in the raw condition, and when its use was stopped the epidemic came to an end.-Zeitschrift für Fleisch und Milchhygiene, January I 894 .

\section{THE PARASITE OF FAVUS.}

MM. Constantin and Sabrayes have studied the course of favus in man, the dog, and the fowl. This study has led them to conclude that three distinct parasites are the cause of the disease in the three species mentioned.

The fungus found in human favus is nearly related to that of the dog, but distinguished from the latter by its appearance in culture, by the invariable structure of its mycelium, and by its colour. The fungus found in favus of the fowl is altogether different from that found in favus of the human subject or the dog.-Recueil de Médecine Vítérinaire.

\section{MEAT AND SAUSAGE POISONING.}

1 GERMAN journal publishes an account of an instance in which over roo persons became ill after eating the flesh of a cow that had been slaughtered while suffering from foot-and-mouth disease. The flesh had been eaten in the 